\title{
INFLUÊNCIA DA RECUPERAÇÃO ELÁSTICA NA INTEGRIDADE DE SUPERFÍCIE DO AÇO SUPERDUPLEX *
}

Adriane Lopes Mougo ${ }^{1}$ Anna Carla Araujo ${ }^{2}$

\section{Resumo}

O efeito de escala é um fenômeno que ocorre durante o microfresamento e trata da relação entre o raio da aresta de corte, a espessura de corte e a microestrutura da peça. O aço superduplex UNS S32750 é um importante material usado na indústria petrolífera que pode ser destinado futuramente para a fabricação de microsensores e microatuadores. No entanto, ainda não existem publicações voltadas para a microusinagem deste aço, seja na análise das forças de corte, na vida útil da ferramenta ou na integridade da superfície usinada. O presente artigo trata do estudo da rugosidade de superfície e da formação de rebarbas após o microfresamento do aço superduplex, considerando diferentes níveis de velocidade de corte e de avanço da ferramenta. A análise dos resultados é realizada considerando que este aço possui microestrutura composta por grãos das fases ferrita e austenita com diferentes taxas de recuperação elástica.

Palavras-chave: Microfresamento; Aço superduplex; Rugosidade de superfície; Rebarba de topo.

\section{INFLUENCE OF ELASTIC RECOVERY IN SURFACE INTEGRITY IN MICROMILLING OF SUPER DUPLEX STAINLESS STEEL}

\begin{abstract}
Size effect is an important phenomenon, which occurs during micromilling, and it deals with the relationship between the radius cutting edge, the uncut chip thickness and the microstructure of the workpiece. Super duplex UNS S 32750 is an important steel used in the deep oil industry that could be applied in the fabrication of microsensors and microactuators. However, there are no previous studies on its micromilling: analysis of cutting forces, tool life and integrity of the machined surface. This paper deals with the study of surface roughness and burr formation after micromilling of superduplex stainless steel, considering different levels of cutting speed and feed per tooth. The analysis of the results considering that this steel has microstructure composed of ferrite and austenite grains with different elastic recovery rates.
\end{abstract}

Keywords: Micromilling; Superduplex steel; Roughness; Burr.

1 Engenharia Mecânica, Doutora, Professora, Departamento Engenharia Mecânica, CEFET/RJ Unidade de Nova Iguaçu, Rio de Janeiro/RJ, Brasil.

2 Engenharia Mecânica, Doutora, Professora, Departamento Engenharia Mecânica, COPPE/UFRJ, Rio de Janeiro/RJ, Brasil. 


\section{INTRODUÇÃO}

O Efeito de Escala, que é um conjunto de fenômenos capaz de descrever o comportamento de um material durante a fabricação em escala reduzida [1], [2], [3]. Segundo Vollertsen et al. [4] este efeito de escala pode ocorrer durante a fabricação de qualquer tipo de material, mas é comumente observado em materiais metálicos devido a deformação plástica. O Efeito de escala em usinagem trata principalmente da relação entre o raio de arredondamento da aresta de corte $\left(r_{e}\right)$ e a espessura do cavaco indeformado ( $\mathrm{t}_{c}$ ) e da microestrutura da peça. Como na microusinagem $t_{c}$ passa a ter a mesma magnitude de $r_{e}$, e muitas vezes $r_{e}>t_{c}$, o ângulo de saída da ferramenta passa a ser negativo, gerando deformações plásticas na superfície da peça que irão comprometer o acabamento e diminuir a vida útil da ferramenta de corte. Somado à isto, para que ocorra a formação do cavaco, é necessário que tc seja maior que uma espessura mínima para formação do cavaco $\left(t_{\mathrm{cm}}\right)$. Isto porque quando $t_{c}<$ $t_{c m}$ o material é "empurrado" à frente da aresta de corte por um mecanismo conhecido por ploughing ou riscamento, que é um processo de conformação e não de usinagem [5]. Se $t_{c}<<t_{c m}$ o cavaco não será formado e a superfície da peça será deformada elasticamente, recuperando a forma após a passagem da ferramenta [6], [7]. Deste modo, a atenção na microusinagem deve ser voltada, no primeiro instante, à medição de $r_{\mathrm{e}}$ e à determinação de $t_{\mathrm{cm}}$, seguida da seleção adequada dos parâmetros de corte. Outra característica importante abordada no efeito de escala é o efeito da microestrutura da peça. Os primeiros trabalhos voltados à microusinagem consideraram a microestrutura do material homogênea, investigando inicialmente a influência dos parâmetros de corte nas forças de corte e na formação do cavaco. No entanto, na microusinagem a quantidade de material removido a cada passagem da aresta de corte pela superfície da peça é muito menor que na usinagem, sem alterar o tamanho dos grãos. Assim, se para o processo convencional a formação do cavaco compreende a união de vários grãos, no microfresamento o cavaco pode ser composto de poucos grãos ou mesmo de um único grão. Quando o corte ocorre dentro de um único grão, as tensões aplicadas à ferramenta são dependentes de vários fatores do material, como a orientação cristalográfica, polimorfismo e fases presentes, causando oscilações de alta frequência das forças de corte [5]. Esta oscilação irá influenciar na performance do processo e no acabamento da peça.

Um ponto importante da relação entre $t_{c}$ e o diâmetro médio dos grãos na mesma ordem de grandeza do raio da aresta de corte é que o material vai sofrer mudanças no estado de tensões e na taxa de deformação. Estas mudanças ocorrem pela variação do estado de tensão de compressivo para trativo durante o escoamento do material e pela alternância da passagem da ferramenta por fases do material ora mais macia ora mais dura. Assim, este mecanismo de formação do cavaco na escala micro é diferente da usinagem convencional. Deste modo, este trabalho tem por objetivo analisar a rugosidade de superfície e a formação de rebarbas após o microfresamento do aço superduplex, considerando dois níveis de velocidade de corte e seis níveis de avanço da ferramenta. A análise dos resultados é realizada considerando que este aço possui microestrutura composta por grãos das fases ferrita e austenita com diferentes taxas de recuperação elástica. Para este trabalho, serão realizados testes de microfresamento, nanodureza e nanoriscamento, além da análise da composição química de cada fase por MEV/EDS.

\section{MATERIAIS E MÉTODOS}


O material utilizado foi o aço inoxidável superduplex UNS S 32750. Para a revelação da microestrutura foi realizado o ataque eletroquímico com reagente composto de 20 $\mathrm{g}$ de $\mathrm{NaOH}$ e $100 \mathrm{ml}$ de água destilada. $\mathrm{O}$ aço superduplex apresenta uma micrografia típica composta de ilhas da fase austenita (coloração mais clara) em uma matriz contínua da fase ferrita (coloração mais escura). A microestrutura é apresentada na Figura (1).

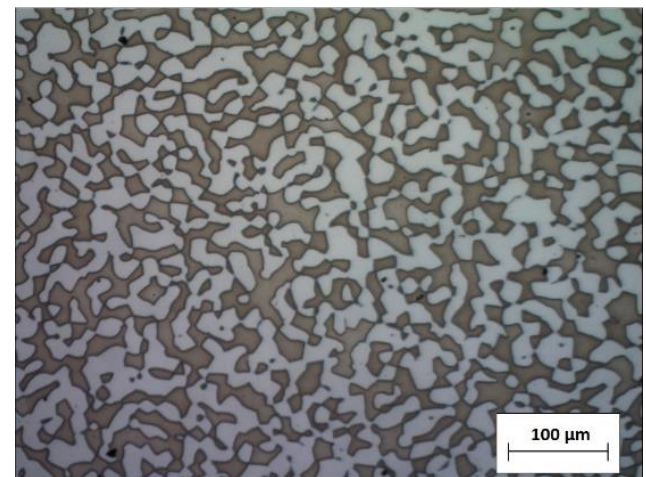

Figura 1. Microestrutura do aço superduplex UNS S 32750.

A composição química de cada fase do aço superduplex foi realizada por Espectroscopia de Energia Dispersiva (EDS) e são apresentadas na Figura (2) e na Tabela (1). A micrografia do aço superduplex foi analisada pelo software Image-Pro Plus para quantificar a fração volumétrica de cada fase do material pelo método de contraste de tonalidade. Os resultados mostraram que a fração volumétrica da fase ferrita foi de $52 \%$ e da fase austenita foi de $48 \%$, distribuídas de modo equivalente.
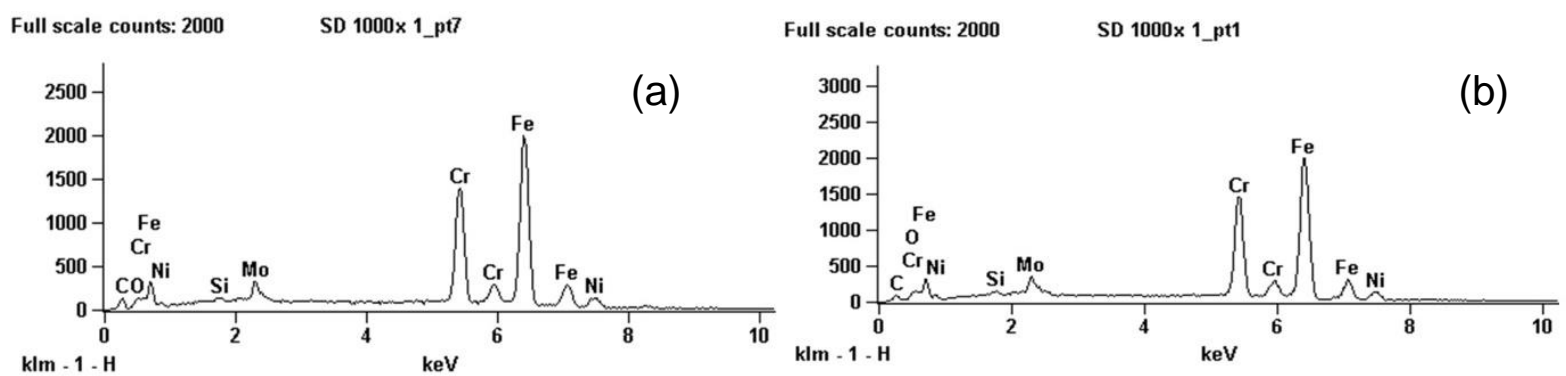

Figura 2. EDS das fases do aço superduplex UNS S 32750: (a) ferrítica e (b) austenítica.

Tabela 1. Resultado da composição química das fases do aço superduplex.

\begin{tabular}{|c|c|c|}
\hline \% em peso & SD - Fase Austenítica & SD - Fase Ferrítica \\
\hline$\% \mathrm{Fe}$ & 53,82 & 52,80 \\
\hline$\% \mathrm{Ni}$ & 6,72 & 4,44 \\
\hline$\% \mathrm{Cr}$ & 20,92 & 23,90 \\
\hline$\% \mathrm{Mo}$ & 2,47 & 3,57 \\
\hline$\% \mathrm{Si}$ & 0,30 & 0,37 \\
\hline
\end{tabular}

O ensaio de nanodureza e nanoriscamento foi realizado com um nanoindentador Agilent Nano-G200 com resolução de deslocamento menor que $0,01 \mathrm{~nm}$, resolução de força de $50 \mathrm{nN}$ e carga máxima de $1 \mathrm{mN}$ com de ciclos de carga e descarga. 
A máquina-ferramenta utilizada neste trabalho foi a microfresadora CNC Mini- Mill/GX da Minitech Machinery Coporation. $O$ controle por Comando Numérico Computadorizado é realizado pelo software Mach3Mill, que é um programa bastante flexível utilizado para controlar máquinas fresadoras ou similares. A rotação da ferramenta é realizada por um motor elétrico da marca Nakanish que possui rotação máxima de $60000 \mathrm{rpm}$ refrigerado à ar comprimido. As especificações técnicas desta máquina tratam do curso limite nas coordenadas $x, y$ e $z$ de $300 \mathrm{~mm}, 288 \mathrm{~mm}$ e 288 $\mathrm{mm}$, respectivamente. A mesa para fixação das peças e/ou dispositivos sensoriais é de alumínio, com dimensão total de 152,4 x 444,5 mm. A fixação na mesa é realizada com parafusos 1/4-20 com distância entre centros de $2,54 \mathrm{~mm}$.

O dinamômetro utilizado foi da marca Kistler do tipo MiniDyn 9256C2 com cabo de conexão do tipo 1967A. A faixa de trabalho deste dinamômetro nas três direções ortogonais é de $-250 \mathrm{~N}$ à $250 \mathrm{~N}$, com alta sensibilidade e frequência natural entre 4,0 a $4,8 \mathrm{kHz}$. A dimensão total do dinamômetro é $80 \times 91 \times 25 \mathrm{~mm}$ e a área útil para posicionamento da peça é de $80 \times 55 \mathrm{~mm}$. O condicionamento dos sinais das forças de corte adquiridos com o minidinamômetro foi realizado com o auxílio de um amplificador de carga da marca Kistler modelo 5070A10100. Foi utilizada uma placa da National Instruments NI USB-6551 e o software LabView Signal Express 2012 para leitura do sinal digital. A frequência de aquisição do sinal de força foi de $40000 \mathrm{~Hz}$.

A ferramenta de corte utilizada nos experimentos foi uma microfresa inteiriça de metal duro com revestimento de nitreto de alumínio titânio (TiAIN-F) (E112F - Standard da Sandvik). A geometria consiste basicamente do diâmetro de $0,8 \mathrm{~mm}, 2$ dentes de corte e diâmetro da haste de $4 \mathrm{~mm}$. Esta ferramenta é indicada para usinagem de aços com dureza menor que $48 \mathrm{HRC}$, aços em geral, ferro fundido, cobre, níquel e titânio. As imagens e a determinação da composição química desta ferramenta foram realizadas com o auxílio do MEV/EDS (marca Zeiss DSM 940) e as medidas do raio da aresta de corte, do raio de ponta e do ângulo de hélice foram medidos com auxílio do software Image J, como apresentadas na Figura (3). Os resultados da medição indicam que o raio da aresta de corte é aproximadamente $2,5 \mu \mathrm{m}$, o raio de ponta é $4 \mu \mathrm{m}$ e o ângulo de hélice ficou em $30^{\circ}$.
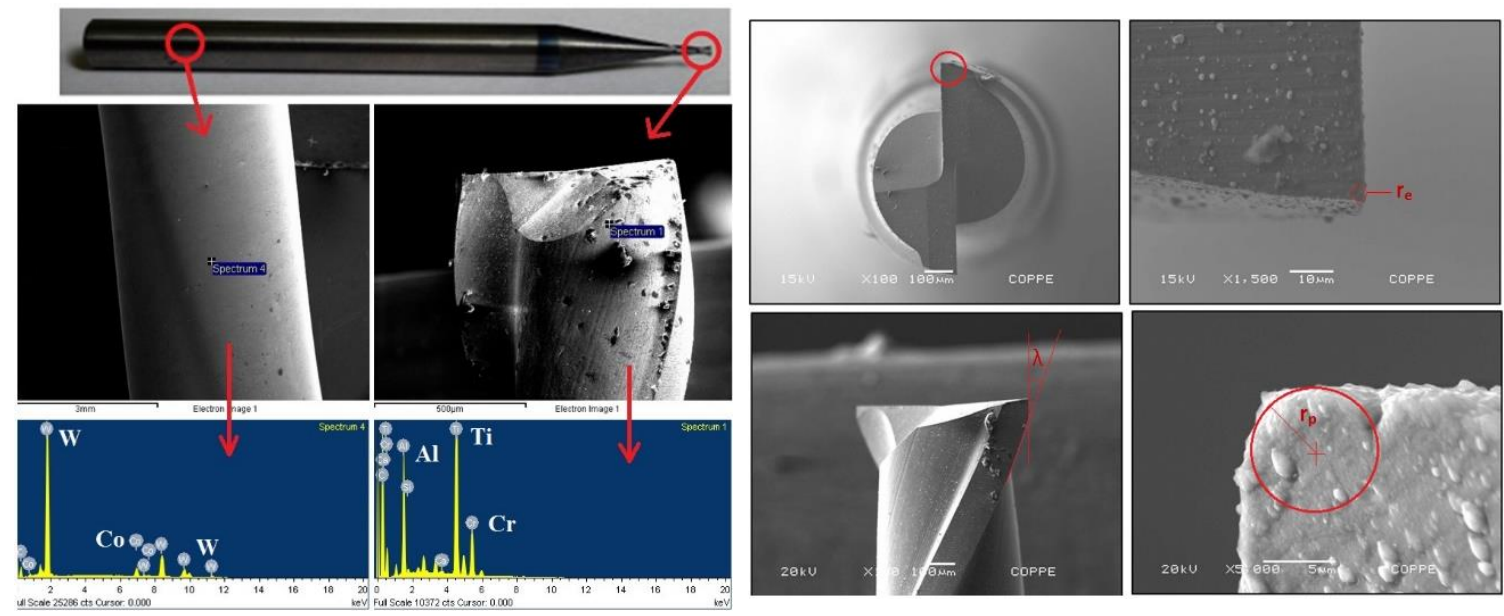

Figura 3. Composição química e medição dimensional da microferramenta de corte.

Para análise da integridade de superfície dos canais microfresados foram analisadas a rugosidade média e altura da rebarba de topo. Para isso, foi utilizado um perfilômetro pertencente a série Form Talysurf Intra da Taylor Hobson, série 0120, capaz de medir 
com alta precisão rugosidade, ondulação, formas e contornos. Este equipamento possui deslocamento transversal de $0.1 \mathrm{~mm}-50 \mathrm{~mm}$, velocidade transversal máxima de $10 \mathrm{~mm} / \mathrm{s}$, campo de medição de + ou - 0,5 mm e velocidade de retorno máximo de $10 \mathrm{~mm} / \mathrm{s}$. Foi utilizado também um apalpador padrão com código de identificação $112 / 2009$, série SY 0637, comprimento do braço de $57,5 \mathrm{~mm}$ e altura do braço até a superfície da peça de $14,7 \mathrm{~mm}$. Este apalpador possui ponta de diamante com $2 \mu \mathrm{m}$ de diâmetro e ângulo de $90^{\circ}$ entre as paredes. Para análise de superfície foi utilizado o Software Ultra Surface Finish V5.

A seleção dos parâmetros de corte fixos e variáveis foi realizada em função dos objetivos deste trabalho. Os parâmetros fixos foram a profundidade, a largura e 0 comprimento de corte. Os parâmetros variáveis foram a velocidade de corte e o avanço por dente. A seleção da velocidade de corte $(\mathrm{Vc})$ foi baseada no Guia de usinagem de aços inoxidáveis da International Molybdenum Association - IMOA. Neste guia o fresamento de faceamento com ferramenta de metal duro é recomendado com $\mathrm{Vc}$ entre $30-50 \mathrm{~m} / \mathrm{min}$ (para desbaste) e 50-70 $\mathrm{m} / \mathrm{min}$ (para acabamento). Assim, decidiu-se por utilizar as velocidades indicadas para desbaste, que correspondem à rotação da ferramenta de 12000 rpm e 20000 rpm, respectivamente.

Considerando inicialmente $\mathrm{tcm}=\mathrm{re} \approx 2,5 \mu \mathrm{m}$ e $\mathrm{ft}=\mathrm{tc}$, espera-se observar mudanças nos resultados da força de corte e da pressão específica de corte quando $\mathrm{ft}<\mathrm{re}$. Deste modo, o avanço por dente foi selecionado entre $1 \mu \mathrm{m}$ e $10 \mu \mathrm{m}$. A Tabela (2) apresenta os parâmetros de corte

Tabela 2. Parâmetros de corte.

\begin{tabular}{|c|c|c|c|}
\hline Material & Experimentos & $\mathbf{f t}(\mathbf{m m} / \mathbf{d e n t e})$ & Rotação $(\mathbf{r p m})$ \\
\hline \multirow{4}{*}{ Superduplex } & 1 & 0.01 & 20000 \\
\cline { 2 - 4 } & 2 & 0.01 & 12000 \\
\cline { 2 - 4 } & 3 & 0.007 & 20000 \\
\cline { 2 - 4 } & 4 & 0.007 & 12000 \\
\cline { 2 - 4 } & 5 & 0.005 & 20000 \\
\cline { 2 - 4 } & 6 & 0.005 & 12000 \\
\cline { 2 - 4 } & 7 & 0.003 & 20000 \\
\cline { 2 - 4 } & 8 & 0.003 & 12000 \\
\cline { 2 - 4 } & 9 & 0.002 & 20000 \\
\hline
\end{tabular}

\section{RESULTADOS E DISCUSSÃO}

As propriedades de cada material estão intimamente ligadas à estrutura. Portanto, para que cada fase do aço superduplex seja caracterizada é necessário realizar, além da composição química, a caracterização das propriedades mecânicas. Como o teste de microdureza produz uma endentação com comprimento aproximado de $73 \mu \mathrm{m}$, seria impossível caracterizar cada fase do superduplex por este teste, já que este aço tem grãos médios de ferrita de $21,1 \mu \mathrm{m}$ e de austenita de 30,2 $\mu \mathrm{m}$. Por isso, nesta etapa foram utilizados os testes de nanoriscamento, Figura (4), e nanodureza, Figura (5a).

O teste de nanoriscamento identificou o coeficiente de atrito $(\mu)$ das regiões desejadas como 0,33. A partir destes valores é possível calcular o ângulo de atrito $(\beta)$ e a espessura mínima do cavaco ( $\left.t_{\mathrm{cm}}\right)$ pelas Equações (1) e (2), respectivamente. O valor de $t_{c m}$ foi de aproximadamente $0,5 \mu \mathrm{m}$. Deste modo, considerando a Tabela (2), a menor espessura do cavaco (quando $f_{t}=1 \mu \mathrm{m} /$ dente) não foi inferior à $t_{c m}$, mas foi 
inferior ao raio da aresta de corte $\left(r_{\mathrm{e}}=2,5 \mu \mathrm{m}\right)$, o que possibilita observar como o efeito de escala atua na rugosidade e na formação da rebarba.
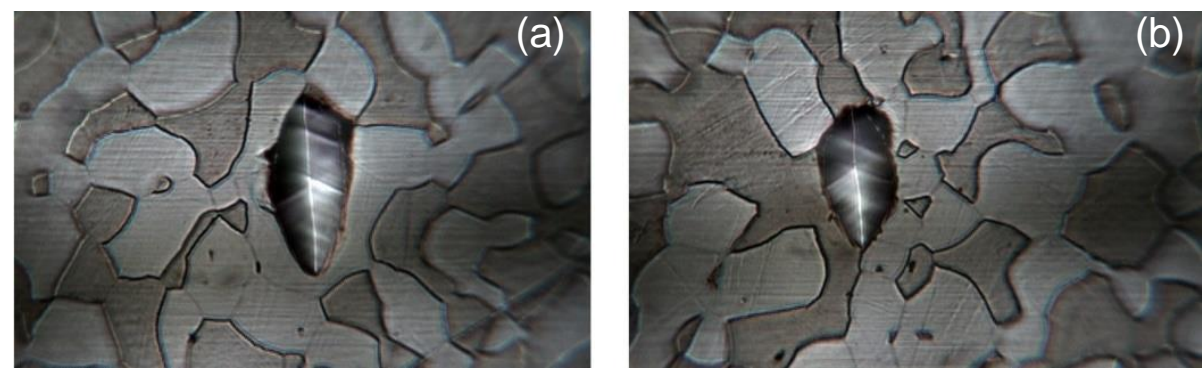

Figura 4. Teste de nanoriscamento nas fases do superduplex. (a) Fase austenita e (b) Fase ferrita.

$$
\begin{aligned}
& \cos \beta=\frac{1}{\sqrt{1+\mu^{2}}} \\
& t_{c m}=r_{e}\left[1-\cos \left(\frac{\pi}{4}-\frac{\beta}{2}\right)\right]
\end{aligned}
$$

Os testes de nanodureza identificaram que a dureza da fase austenítica é superior à da fase ferrítica, pois nas ligas a base de níquel a estrutura cúbica de face centrada pode ser endurecida por precipitação de carbonetos ou pela precipitação de compostos intermetálicos formados principalmente quando o material apresenta alto teor de cromo e molibdênio, como foi visto na Tabela (1). A precipitação empobrece estes elementos nas regiões adjacentes aos carbonetos formados na matriz, diminuindo o módulo de elasticidade e tornando o material mais resiliente. Por consequência, a taxa de recuperação elástica $(\rho)$ da fase austenítica chega a ser $3 \%$ maior nos aços superduplex que nos aços AISI 316, por exemplo. Esta propriedade do material calculada pela Equação (3), onde $F_{\max }$ é a força máxima de indentação, $S$ ( $\mathrm{dF} / \mathrm{dh}$ ) é a rigidez da curva de descarregamento e $\mathrm{h}_{\max }$ é a profundidade alcançada na máxima de penetração do indentador, como apresentado na Figura (5b).
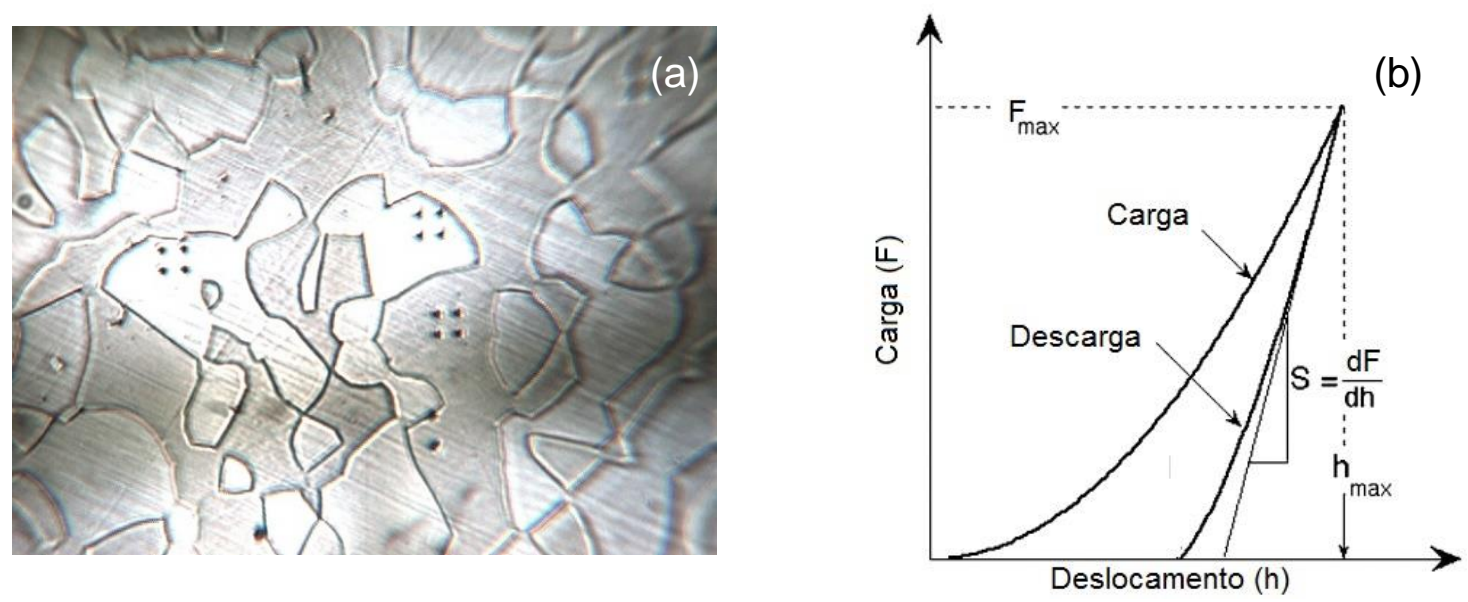

Figura 5. Teste de nanoindentação. (a) Impressão do nanoindentador e (b) Esquema do processo de penetração.

$$
\rho=\frac{F_{\max }}{\left(\frac{d F}{d h}\right) h_{\max }}(3)
$$


Tabela 3. Propriedades mecânicas das fases do aço superduplex.

\begin{tabular}{|l|c|c|}
\hline \multicolumn{1}{|c|}{$\begin{array}{c}\text { Propriedades } \\
\text { Mecânicas }\end{array}$} & $\begin{array}{c}\text { Fase } \\
\text { Austenítica }\end{array}$ & $\begin{array}{c}\text { Fase } \\
\text { Ferrítica }\end{array}$ \\
\hline Coeficiente de atrito & 0,33 & 0,33 \\
\hline Nanodureza $(\mathrm{GPa})$ & 6,92 & 6,59 \\
\hline Módulo de Elasticidade $(\mathrm{GPa})$ & 214,02 & 244,39 \\
\hline Recuperação elástica $(\%)$ & 17,15 & 14,09 \\
\hline
\end{tabular}

A rugosidade de superfície foi medida na direção de avanço: três medidas por canal. A influência dos parâmetros de corte na rugosidade média foi verificada usando os experimentos de 1 a 8 . Considerando uma significância de $5 \%$, os resultados por análise de variância mostraram que $o$ avanço por dente $\left(\mathrm{f}_{\mathrm{t}}\right)$ apresenta maior influência na rugosidade média $\left(R_{a}\right)$ que a velocidade de corte $\left(V_{c}\right)$. A Figura (6) apresenta a evolução de $R_{a}$ em função de $f_{t}$ considerando $V_{c}=50 \mathrm{~m} / \mathrm{min}$. Os resultados seguem àqueles encontrados na literatura, onde a rugosidade é diretamente influenciada por $\mathrm{f}_{\mathrm{t}}$, quando o raio da aresta de corte $\left(\mathrm{r}_{\mathrm{e}}\right)$ permanece constante. Deste modo, é possível observar que o valor médio de Ra aumenta com o aumento de ft.

No entanto, o intervalo de erro para ft $>5 \mu \mathrm{m} /$ dente é maior do que aquele observado para ft entre $1 \mu \mathrm{m} /$ dente e $3 \mu \mathrm{m} /$ dente. Isso pode ser explicado pela atuação da recuperação elástica diferenciada entre as fases do aço superduplex. Malekian et al. (2012) apresentaram a altura da recuperação elástica (tre) como uma função da taxa de recuperação elástica $(\rho)$ e da espessura do cavaco $\left(t_{c}\right)$, como mostrado na Equação (4). Para esta equação considera-se que $t_{c}=f_{t}$ e que $\rho=17.2 \%$ e $14.1 \%$ para as fases austenítica e ferrítica, respectivamente

$$
t_{r e}=\rho t_{c}
$$

Assim, quanto maior for o valor de tc, maior será a diferença de ter entre as fases do aço superduplex e, por consequência, maior será o intervalo de erro nos resultados da rugosidade média. Por exemplo, quando $\mathrm{f}_{\mathrm{t}}=1 \mu \mathrm{m} /$ dente e $5 \mu \mathrm{m} /$ dente a diferença entre os valores de tre das fases austenítica e ferrítica são de 0,03 $\mu \mathrm{m}$ e $0,15 \mu \mathrm{m}$, respectivamente. Isso mostra que a integridade da superfície microfresada é influenciada não somente pelos parâmetros de corte, mas também pelas propriedades mecânicas das fases presentes em um material com microestrutura heterogênea.

De modo geral, a condição ideal de microfresamento para baixos valores de rugosidade de superfície é quando $\mathrm{f}_{\mathrm{t}}<\mathrm{r}_{\mathrm{e}}$. No entanto, pelo conceito de efeito de escala, quando esta condição é alcançada, a força de corte e a pressão específica de corte apresentam um aumento não linear.

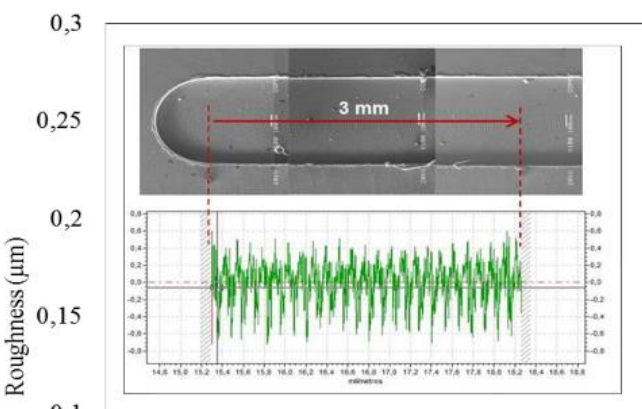


Figura 6. Influência do avanço da ferramenta na rugosidade média do aço superduplex.

As rebarbas são deformações plásticas ocasionadas pela alta tensão de compressão na peça durante a passagem da ferramenta. Estas deformações tornam-se maiores quando $\mathrm{f}_{\mathrm{t}}<\mathrm{r}_{\mathrm{e}}$ e a ocorrência está diretamente relacionada com o efeito de escala e depende especialmente das características microestruturais do material da peça, do raio da aresta de corte e parâmetros de corte.

Para a altura da rebarba de topo foram realizadas 10 medições transversais em cada canal microfresado. Com os resultados dos experimentos de 1 a 8 foi possível observar que o avanço da ferramenta apresenta maior influência na formação da rebarba. A Figura (7) apresenta a influência de $f_{t}$ na formação da rebarba de topo considerando $\mathrm{V}_{\mathrm{c}}=50 \mathrm{~m} / \mathrm{min}$.

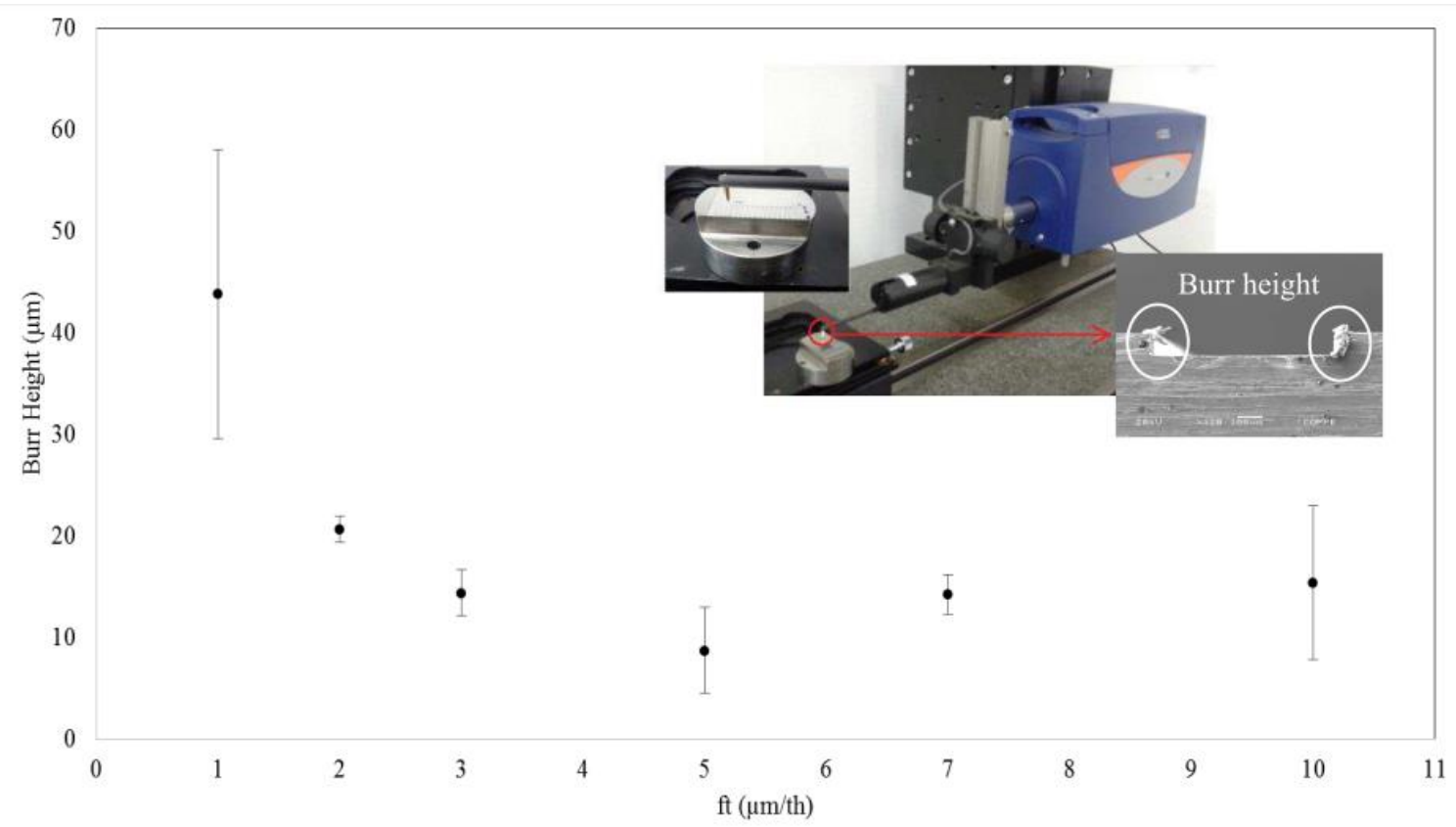

Figura 7. Influência do avanço da ferramenta na rebarba de topo do aço superduplex.

É importante observar que nesta figura os resultados se referem aos valores médios entre a rebarba de topo na entrada e na saída do dente. O aumento da rebarba de topo no microfresamento ocorre principalmente quando a razão entre $t_{c}$ e $r_{e}$ é baixa ( $f_{t}$ $=1 \mu \mathrm{m} /$ dente e $2 \mu \mathrm{m} /$ dente), pois o efeito ploughing faz com que uma porção do 
material da peça seja empurrado à frente da aresta de corte para as laterais dos canais microfresados.

Para fazer uma breve análise qualitativa da formação destas rebarbas, foram feitas imagens na lateral dos canais microfresados. Pode-se observar que a formação de rebarba é maior e mais descontínua quando ft $=7 \mu \mathrm{m} /$ dente, como mostrado na Figura (8a). Nesta figura também é possível observar o efeito maior do ploughing devido a maior quantidade de rebarba formada na saída da aresta de corte (downmilling). Apesar de $t_{c}>t_{c m i n}$ quando $f_{t}=7 \mu \mathrm{m} /$ dente e o mecanismo de corte prevalecer em relação ao ploughing, este sempre vai existir, em maior ou menor intensidade. Por isso, quando se diminui o valor de $f_{t} e$, por consequência, se aumenta o efeito ploughing, a altura da rebarba de topo aumenta, como foi apresentado na Figura (8a). Na Figura (8b), onde $\mathrm{f}_{\mathrm{t}}=10 \mu \mathrm{m} /$ dente, a rebarba de topo é menor e mais contínua.
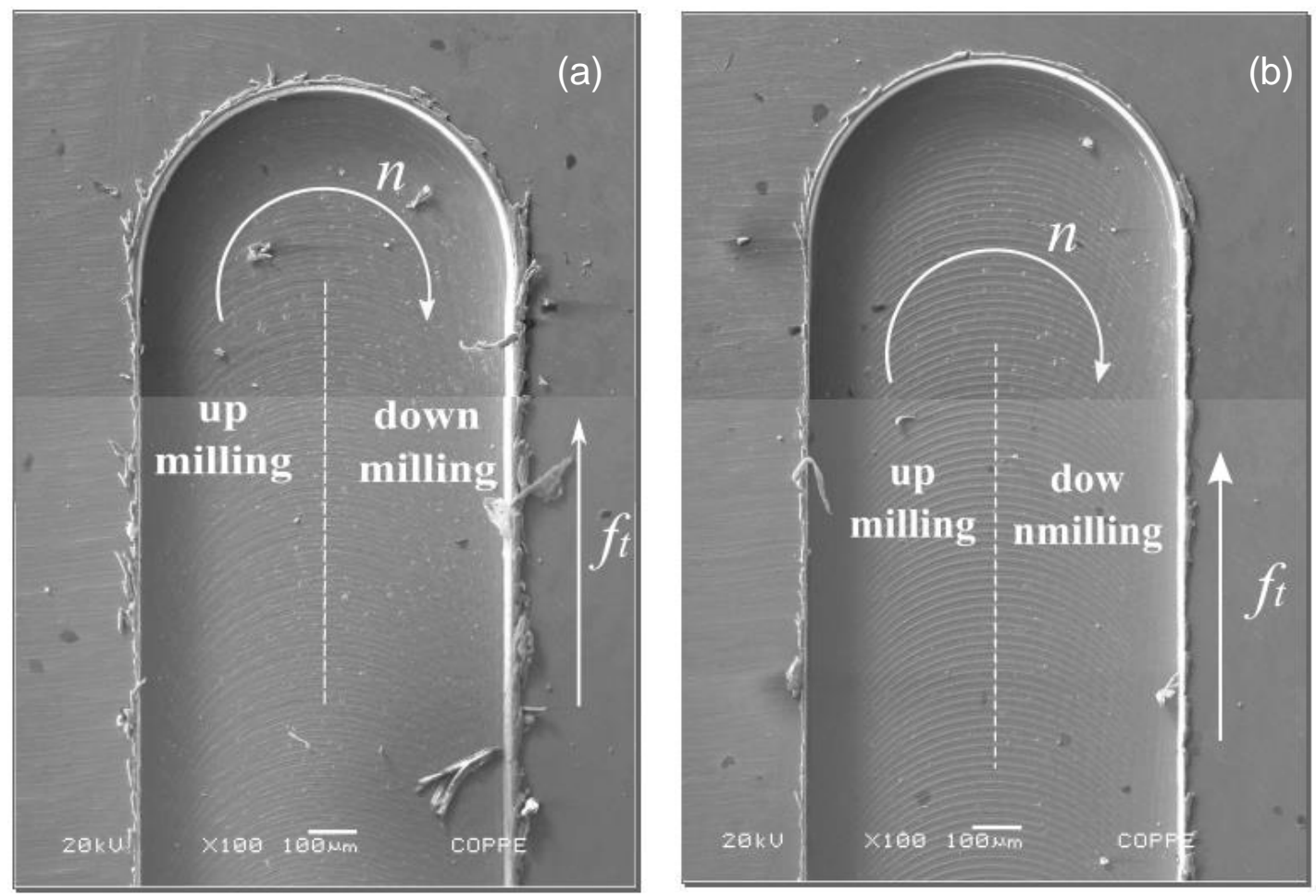

Figura 8. Formação da rebarba de topo. (a) $\mathrm{ft}=7 \mu \mathrm{m} /$ dente e (b) $\mathrm{ft}=10 \mu \mathrm{m} /$ dente.

\section{CONCLUSÕES}

Este trabalho apresentou um estudo sobre o microfresamento do aço superduplex e a influência dos parâmetros de corte na integridade de superfície da peça. O material de estudo foi o aço inox superduplex UNS S32750. Os parâmetros de corte analisados foram a velocidade de corte e o avanço por dente. Foi realizado um estudo da integridade superficial do aço superduplex com a análise de rugosidade da superfície e a formação da rebarba de topo nas laterais dos canais microfresados. As principais conclusões deste trabalho são apresentadas.

- O avanço da ferramenta é o parâmetro de corte com maior influência na rugosidade média e na formação da rebarba de topo.

- Foi observado que a rugosidade média aumenta com o avanço da ferramenta. Este resultado já era esperado, pois a rugosidade de uma superfície usinada é 
diretamente influenciada pelo avanço da ferramenta e pelo raio da aresta de corte, que neste trabalho foi considerado constante $\left(r_{e}=2,5 \mu \mathrm{m}\right)$. No entanto, o intervalo de erro foi maior para $f_{t} \geq 5 \mu \mathrm{m} /$ dente devido a maior variação na recuperação elástica das fases do aço superduplex.

- A altura da rebarba de topo foi observado quando $f_{t}<r_{e}$. Quando a razão entre $f_{t}$ e $r_{e}$ é baixa, o efeito ploughing atua mais severamente no processo de formação do cavaco, ou seja, um volume maior de material da peça é empurrado à frente da aresta de corte para as laterais do canal, formando as rebarbas.

- Imagens por MEV confirmaram que para o avanço menor a rebarba de topo se forma na lateral do canal de modo descontínuo e, principalmente, na lateral de saída da aresta de corte (downmilling).

\section{Agradecimentos}

Os autores agradecem ao auxílio do Conselho Nacional de Desenvolvimento Científico e Tecnológico - CNPq pela bolsa de Doutorado referente ao processo 142275/2012-3, aplicado entre 08/12 a 01/2015.

\section{REFERÊNCIAS}

1 Mian A, Driver N, Mativenga P. Identification of factors that dominate size effect in micro-machining. International Journal of Machine Tools and Manufacture. 2011;51(5): 383-394.

2 Aramcharoen A, Mativenga P. Size effect and tool geometry in micromilling of tool steel. Precision Engineering. 2009;33(33): 402-407.

3 Bissacco G, Hansen H, Chiffre L D. Size Effects on Surface Generation in Micro Milling of Hardened Tool Steel. CIRP Annals - Manufacturing Technology. 2006;55(1): 593596.

4 Vollertsen F, Biermann D, Hansen $\mathrm{H}$. Size effects in manufacturing of metallic components. CIRP Annals - Manufacturing Technology. 2009;58(2):566-587.

5 Ramos AC, Autenrieth $\mathrm{H}$, Straub T. Characterization of the transition from ploughing to cutting in micro machining and evaluation of the minimum thickness of cut. Journal of Materials Processing Technology. 2012;212(3):594-600.

6 Malekian M, Mostofa M, Park S. Modeling of minimum uncut chip thickness in micro machining of aluminum. Journal of Materials Processing Technology. 2012;212(3):553559.

7 Vogler MP, Devor RE, Kapoor SG. On the Modeling and Analysis of Machining Performance in Micro-Endmilling, Part I: Surface Generation. Journal of Manufacturing Science and Engineering. 2004;126(4):685-694.. 